\title{
EFFECT OF UV-LIGHT AND $\gamma$ - IRRADIATION OF APPLE JUICE ON ORGANOCHLORINATED PESTICIDE RESIDUES
}

(Received: 3.12.2008)

\author{
By \\ S. M. Herzallah \\ Department of Nutrition and Food Science, Faculty of Agriculture, Mu'tah University, Karak-Jordan
}

\begin{abstract}
This study was conducted to evaluate the effect of UV-light and $\gamma$-irradiation on the organochlorine pesticide $\left(\mathrm{OCP}^{\prime} \mathrm{s}\right)$ residues in apple juice. The use of $\gamma$ - irradiation $\left({ }^{60} \mathrm{Co}\right)$ led to a degradation percentage of $30 \%$ after a dose of $25 \mathrm{kGray}$, while the irradiation with $5 \mathrm{kGray}$ was found to produce insignificant effect on OCP's residues when compared with the control. On the contrary, the use of the UVC for a period of $25 \mathrm{~min}$ led to $90 \%$ reduction of the most OCP's. Moreover, a 30-min increase in the exposure time of the contaminated apple juice led to almost complete destruction of OCP's after exposure to UVC-ray. Therefore, the exposure time was found to be significantly $(\mathrm{P}<0.05)$ effective in complete degradation of OCP's when exposed to UV-light, while not effective in complete removal of the OCP's in the case of $\gamma$ - irradiation regardless of the treatment dose.
\end{abstract}

Key words: organochlorine pesticides (OCP's), $\gamma$-irradiations, UVC (UV-light of $254 \mathrm{~nm})$ and SPME.

\section{INTRODUCTION}

Pesticides are chemical compounds that are designed widely to be used in agricultural products to control pests and/ or to increase the plant's resistance against them (USFDA, 2006; Bernard et al., 2004). These chemicals or their residues in plant fruits are normally found in various food stuffs which can be poisonous to plants, animals or cause problems for human health (EU, 2006; Colborn et al., 1998). Some pesticides possess higher toxic effect that can cause illness or death to human at very small levels. Moreover, safer pesticides are capable of causing irritation to human organs (nose, eyes, skin, or mouth) through inhalation, contact or dermal and oral exposures. Although the major source of pesticide residues could be fruit and vegetables, they can also be taken indirectly through animal products such as meat and milk as a result of animal exposure to pesticides through feed contaminated with these chemicals, which are usually found in food and food products given to animals. The chlorinated organic pesticides: $p-p$ DDT, aldrin, endrin, dieldrin and heptachlor (the most fat-soluble) show a higher degree of stability ( Nandong et al., 2005; Ou et al., 2003) and accumulation in animal tissues (meat and meat products) and in milk fat (Abdul-Wahab et al., 2004). The organochlorinated pesticide residues could be partially or totally affected by many factors such as processing conditions, heat treatment, and storage conditions. These food products could be treated with UVC ray ( Anonmyous, 1999 ; Churey and Padilla-Zakou, 1998 ) or radiated with $\gamma$-rays as a method of preservation (Sastry et al., 2000; Guerrero-Beltrin, 2004). Therefore, the objective of this study was to find the effect of $\gamma$-rays, and UVlight (UVC-254nm) on the OCP's residues in commercially produced apple juice.

\subsection{Reagents}

\section{MATERIALS AND METHODS}

$\mathrm{N}$-hexane, toluene, and acetonitrile were of pesticide grade purchased from BDH (BDH, Dorset, England). Ethyl acetate (HPLC grade) was obtained from (Pest Scan, Dublin, UK). Anhydrous sodium sulfate $99 \%$ (Scharlau, Spain) was heated at $500^{\circ} \mathrm{C}$ for five hours, cooled and stored in the oven (Memmert, GmbH, Germany), sodium chloride (analytical grade) of 99\% were from Fluka ( Fluka, Switzerland). Florisil of 60-100 mesh (Riedeldehäen, Germany) was activated before use at $550^{\circ} \mathrm{C}$ for six hours and stored at $130^{\circ} \mathrm{C}$ in the oven. Whatman filter paper of $55 \mathrm{~mm}$ in diameter used in sample preparation was purchased from Whatman ( GmbH, Germany).

\subsection{Equipment}


The gas chromatograph used (Shimadzu 2010, Japan) was equipped with a split-splitless injector, ${ }^{63} \mathrm{Ni}-\mathrm{ECD}$ (electron capture detector) and a capillary column (rtx.5, Cross bond 5\% diphenyl, 95\% dimethyl polysiloxane 30 meter, $0.25 \mathrm{~mm}$ id, 0.1 $\mu \mathrm{m} \mathrm{df})$. A vortex mixer, hot plate, rotary evaporator (Heidolph, WB2000, Germany), water chiller circulator (Julab, Germany), vacuum pump 800 mbar (Thermoline, Germany) and SPME fiber assembly of $100 \mu \mathrm{m}$ polydimethyl siloxane coating for manual hold (Supelco, USA) and SPME fibber assembly of $30 \mu \mathrm{m}$ Poly dimethyl siloxane coating (Supelco, USA) were used in OCP's extraction and quantification. UV-light lamp (length $34.3 \mathrm{~cm}$ ), cell diameter of $6.5 \mathrm{~cm}, 200-250$ volts, $50-60 \mathrm{~Hz}$ frequency, power consumption of $12 \mathrm{~W}$, and inlet / outlet power size $1 / 2 \mathrm{mnpt} / 3 / 8 \mathrm{fnpt}$ was used in the treatment of OCP's contaminated juice samples. Analytical balance of four digits with a maximum weight of $310 \mathrm{~g} \pm 0.0001 \mathrm{~g}$ (Shimadzu, Japan), and hamilton syringes (Hmilton, Switzerland) of 1, 10, 100 and $500 \mu \mathrm{l}$ were used in standard preparation and GC-ECD analysis.

\subsection{Pesticide Standards}

A Stock OCP's standard mixture of 2000 $\mathrm{ug} / \mathrm{mL}$ from Hexachlorobenzene ( $\alpha, \beta, \gamma, \delta, \mathrm{BHC})$, Heptachlor, Aldrin, Heptachlo epoxide, $\gamma$-chlordane, Endosulfan I, $\alpha$-chlordane, Diedrin, 4,4' -DDE, Endrin, Endosulfan II, 4,4'-DDD, Endrin aldehyde, Endosulfan sulfate, 4,4'-DDT, Endrin ketone, and Methoxychlor dissolved in hexane: toluene (50:50) were obtained from Supelco (47426-U, USA).

\subsection{Standard preparation and Gas \\ chromatograph parameters:}

Working standard of concentrations $0.50,1.12$, 12.40 , and $20.00 \mathrm{ppb}( \pm 0.01)$ for each pesticide were prepared from the stock OCP's standard mixture and $1-\mu \mathrm{L}$ of each prepared working standard was injected into the GC through the injection port. A splitless injector mode was used and the temperature set at $250^{\circ} \mathrm{C}$. The oven temperature was programmed from $150^{\circ} \mathrm{C}$ (held for $1 \mathrm{~min}$ ) to $275^{\circ} \mathrm{C}$ (at intervals of $5^{\circ} \mathrm{C} / \mathrm{min}$ ) and held for 2 minutes then to $280^{\circ} \mathrm{C}$ at $5^{\circ} \mathrm{C} / \mathrm{min}$. The total run time was 28 minutes and the detector temperature was maintained at $310^{\circ} \mathrm{C}$.

\subsection{Treatments and OCP's Extraction}

A sample of $4000 \mathrm{ml}$ of the prepared juice (free of the chlorinated pesticide residues) was spiked with $100 \mathrm{ppb}$ of each OCP's standard mixture. The spiked solution was then divided into 36 equal portions and filled into glass bottles of
$100 \mathrm{ml}$ capacity and treated in triplicate as follows: Fifteen samples of these juice bottles were irradiated with $\gamma$-ray $\left({ }^{60} \mathrm{Co}\right.$, Jordan Nuclear Authority) of $5,10,15,20$, and 25 kGray (51 $\mathrm{min} / \mathrm{kGray}$ ), Eighteen bottles were exposed to UV light for $5,10,15,20,25$ and $30 \mathrm{~min}$, and three bottles were kept as control samples.

About $10 \mathrm{ml}$ from the extract of the treated and the control juice samples were passed through the SPE (Supelco, USA) florisil column (500 mg, 6-ml, activated with $6 \mathrm{ml}$ hexane). The eluate with diethyl ether: hexane (15:85) out of the SPE column was collected and the solvent removed under vacuum to dryness, then the residues resuspended in $3.5 \mathrm{ml}$ acetonitrile in amber glass vials ( 4-ml capacity) contained a stirring rod of 2-mm length. The vial placed on a hot plate at $40{ }^{\circ} \mathrm{C}$ and the SPME fiber polydimethylsiloxane of the $100 \mu \mathrm{m}$ was immersed in the mixture while being stirred (at $2400 \mathrm{rpm}$ ) for $35 \mathrm{~min}$ to extract the OCP's. The extracted OCP's on the SPME fiber were then injected in the GCECD.

2.6. Limits of detection (LOD) and Recovery tests

The limits of detection for chlorinated pesticides were determined by injection of concentrations of $0.50 \mathrm{ppb}$ and then increased until the concentration of 20-ppb reached by successive dilution of the OCP's. The lower concentration measured from peak/noise ratio was found for the solvent (hexane: toluene), the peak area was then increased and decreased by two standard deviations $( \pm 2 \mathrm{SD})$ for the nineteen OCP's mixture. The lower concentration was calculated and injected for ten times in the GC. The recovery tests were evaluated for the nineteen OCP's compounds in apple-juice samples. This was performed by spiking the apple juice sample with $10 \mu \mathrm{l}$ from the pesticides mixture (100 ppb) and re-extracted with the SPME procedures.

\subsection{Statistical analysis}

The data were evaluated and compared through arithmetic mean, standard deviation and General linear model (GLM) regression line using the SAS (SAS Institute, 2000) package for windows.

\section{RESULTS}

The chromatogram of the nineteen organochlorinated pesticides (OCP's) standard mixture using the SPE followed by SPME and separated with a GC column of non-polar (5\% diphenyl, 95\% dimethyl polysiloxane) stationary phase is shown in Figure1. It is obvious that all the OCP's were well resolved by this column and the 
concentrations can be calculated with higher precision. The reproducibility as relative standard deviation of retention times of 15 replicated (runs) of the nineteen OCP's standard mixture was less than $2.1 \%$. The precision as relative standard deviation of peak area of 15 replicated runs of the OCP's standard mixture was also less than $4.2 \%$ and the minimum detectable concentration of each OCP's was $0.50 \mathrm{ppb}$. The efficiency of the SPME method for extracting the chlorinated pesticide (expressed as recovery \%) of the spiked apple juice sample ( $100 \pm 0.10 \mathrm{ppb})$ for the nineteen OCP's mixture and extracted in four replicates with SPME fibred needle expressed as percentage of the recoveries for each of the nineteen OCP's are presented in Table 1 . The recovery percentages of all of the tested OCP's were between $99 \%$ and 97\% with standard deviation between 0.80 and 2.03. The effect of the tested parameters $(\gamma$-irradiation, UVlight) is presented in Table 2. The results showed that the $\gamma$-irradiation of $5 \mathrm{kGray}$ and the exposure to UVC-light for $\leq 5 \mathrm{~min}$ were insignificantly ( $p>$ 0.05) affecting the pesticide residues for all of the nineteen OCP's (Table 2). The treatment of the contaminated apple juice with UVC and $\gamma$ irradiation shows an increase in degradation power with either increasing the dose of irradiation, or increase of exposure time. For example, the degradation percentage of $\alpha-\mathrm{BHC}$ was found to be $1 \%$ after a dose of $5 \mathrm{kGray}$ compared to $30 \%$ after a dose of 25 KGray, whereas, the UV-light treatment caused less than detection $1 \%$ and $100 \%$ reduction after 30 min exposure to UV- light.

\section{DISCUSSION}

The linear regression and the correlation coefficients of the nineteen OCP's compounds used in this study $[\alpha$-BHC, $\beta$-BHC, $\gamma$-BHC(lindane), $\delta$ BHC, Heptachlore, Aldrin, Heptachlore epoxide, gama-chlorodane, endosulfan I, alpha-chlorodine, Dieldrine, 4,4'-DDE, Endrine, Endosufan II, Endrine aldehyde, Endosulfan sulfate, 4,4'DDT and Endrine ketone] showed linear response in the range of 0.5 to $20 \mu \mathrm{g} \mathrm{kg}^{-1}$. For instance, the $\mathrm{R}$ value for $\alpha-\mathrm{BHC}$ and heptachlore were 0.9999 and 0.987 , respectively. The linearity and high correlation values were in agreement with the $\mathrm{R}$ values of OCP's obtained by Frias et al. (2001), who found that the R values for $\gamma$-BHC (lindane), Aldrin, p,p'DDE and o,p'-DDT were 0.9971 for p,p'-DDT and 0.9999 for Lindane. The time required to determine the OCP's was $17.34 \mathrm{~min}$ which is very reasonable and short to determine the nineteen organochlorinated compounds tested by GC-ECD. The sensitivity of the extraction procedure and analysis were also very high when compared with the detection limit which is up to $0.50 \mu \mathrm{g} \mathrm{kg}^{-1}$. The detection limit determined was also in agreement with the results obtained by (Frias et al., 2001; Beltan et al, 2003; Wurl and Obbard, 2005; Stepan et al., 2005).

The recovery of the OCP's determined by the SPME technique indicated that when apple juice spiked with $100 \mathrm{ppb} \pm 1.0$ of the nineteen organochlorinated pesticides (OCP's) were between 99 and $97 \%$ (Table 1). The recoveries of the 13 organochlorinated pesticide residues of $\alpha$-BHC , $\beta$ BHC, $\gamma$-BHC (lindane) $\delta$-BHC, Aldrin, Heptachlor epoxide , $\gamma$-chlordane, Endosulfan I, Endrine , 4,4'DDD, Endrine aldhyde, Endosulfan sulfate, and Endrine ketone were $99 \%$, whereas, it was $98 \%$ for Heptachlor, Dieldrine , 4,4'DDE, Endosulfan II , 4,4'DDT.

These recovery results were in agreement with the recoveries of OCP's found by (Frias et al., 2001; Waliszewski et al., 2004) and higher than the recoveries of some organophosphorous pesticides obtained by Chai et al. ( 2006) who found that the recoveries range between 85 to $90 \%$ for Diazinon, chlorothalinol, malathion, chlorpyrifos, quinalphos, and profenofos. The effect of $\gamma$-irradiation and the UV-light on the degradation of chlorinated pesticides of three replicates of six apple juice samples spiked with $100 \mathrm{ppb}$ of each OCP's in the standard mixture and then exposed to UV-light each for 5, 10, 15, 20, 25 and $30 \mathrm{~min}$ are reported in Table 2. The data indicates that all OCP's exhibit different levels of stability, against both $\gamma$-irradiation and UVC-light treatments and vary with the exposure time. The degradation levels of the tested OCP's were less than or equal $30 \%$ for $\gamma$ - irradiation and range from $<1.0$ to $100 \%$ after $30 \mathrm{~min}$ of exposure to UV-light. These results are in consistence with the degradation of OCP's resulted from UV treatment of milk and butter oil found by Li and Bradley (1968) for the degradation of methoxychlor compound.

It is also, observed that the exposure of OCP's to $\gamma$ - irradiation of $5 \mathrm{kGray}$ and UV-light for $5 \mathrm{~min}$ were without any noticeable effect. The higher rate of OCP's degradation by UV-light could be attributed to high-energy photons that are usually generated by the UV- light which breaks down molecular bonds in organic molecules and produce -OH radicals that accelerate the photon-oxidation process (Benitez et al., 2006 ). Therefore, using UV- 


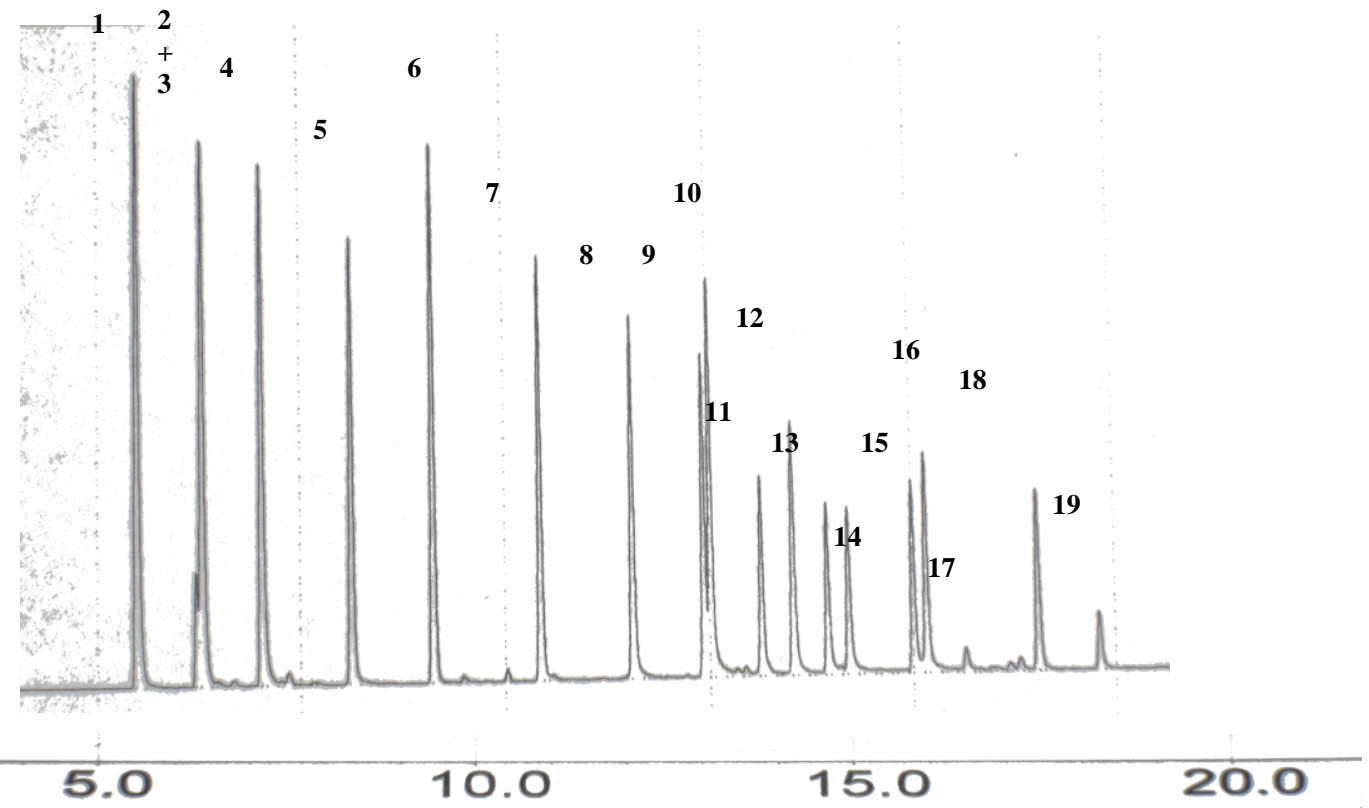

Time (min)

Fig. (1): OCP's standard chromatogram analyzed by GC/ECD.

(where: 1- $\alpha$-BHC, 2- $\beta$-BHC, 3- $\gamma$-BHC (lindine), 4- $\delta$-BHC, 5-heptachlore, 6-aldrin, 7-heptachlore epoxide, 8- $\gamma$-chlorodine, 9-endosulfan I, 10- $\alpha$ - chlorodine, 11- dieldrine, 12-4,4'-DDE, 13 -endrine, 14- endosulfan II, 15-4, 4'-DDD, 16- endrine aldehyde, 17- endosulfan sulfate, 18- 4, 4'-DDT, and 19-endrine ketone).

Table 1: Organochlorinated pesticide recovery percentage from apple juice samples spiked with $100 \pm 1.0 \mathrm{ppb}$ of mixed OCP's standard.

\begin{tabular}{|c|l|c|c|}
\hline ID & Name $^{1}$ & Retention Time & \% Recovery $^{2}$ \\
\hline 1. & $\alpha-$ BHC & 5.50 & $99 \pm 1.20$ \\
\hline 2. & $\beta$-BHC & 6.26 & $99 \pm 0.96$ \\
\hline 3. & $\gamma$-BHC(lindane) & 6.31 & $99 \pm 0.87$ \\
\hline 4. & -BHC & 7.05 & $99 \pm 1.00$ \\
\hline 5. & Heptachlore & 7.38 & $98 \pm 2.00$ \\
\hline 6. & Aldrin & 8.14 & $99 \pm 1.60$ \\
\hline 7. & Heptachlore epoxide & 9.14 & $99 \pm 0.86$ \\
\hline 8. & gama-chlorodine & 10.45 & $99 \pm 0.80$ \\
\hline 9. & endosulfan I & 11.58 & $99 \pm 0.98$ \\
\hline 10. & alpha-chlorodine & 12.45 & $99 \pm 0.98$ \\
\hline 11. & Dieldrine & 12.55 & $98 \pm 1.07$ \\
\hline 12. & 4,4 -DDE & 13.16 & $98 \pm 1.17$ \\
\hline 13. & Endrine & 13.55 & $99 \pm 1.00$ \\
\hline 14. & Endosufan II & 13.99 & $98 \pm 1.90$ \\
\hline 15. & $4,4 '$-DDD & 14.24 & $97 \pm 2.03$ \\
\hline 16. & Endrine aldehyde & 15.03 & $99 \pm 0.83$ \\
\hline 17. & Endosulfan sulfate & 15.19 & $99 \pm 0.90$ \\
\hline 18. & 4,4 'DDT & 16.57 & $98 \pm 1.33$ \\
\hline 19. & Endrine ketone & 17.34 & $99 \pm 1.33$ \\
\hline
\end{tabular}

${ }^{1}$ Confirmation of each OCP in the mixed standard is based on the reference chromatogram provided by SUPELCO Comnanv. ${ }^{2}$ Values are means of four replicates $(n=4) \pm$ SD and the retention time window of $2.5 \%$. 
Effect of uv-light and $\gamma$-irradiation of apple juice .

Table 2: Effect of $\gamma$-irradiation and UVC-ray of apple juice on Chlorinated pesticide residues levels ${ }^{1}$.

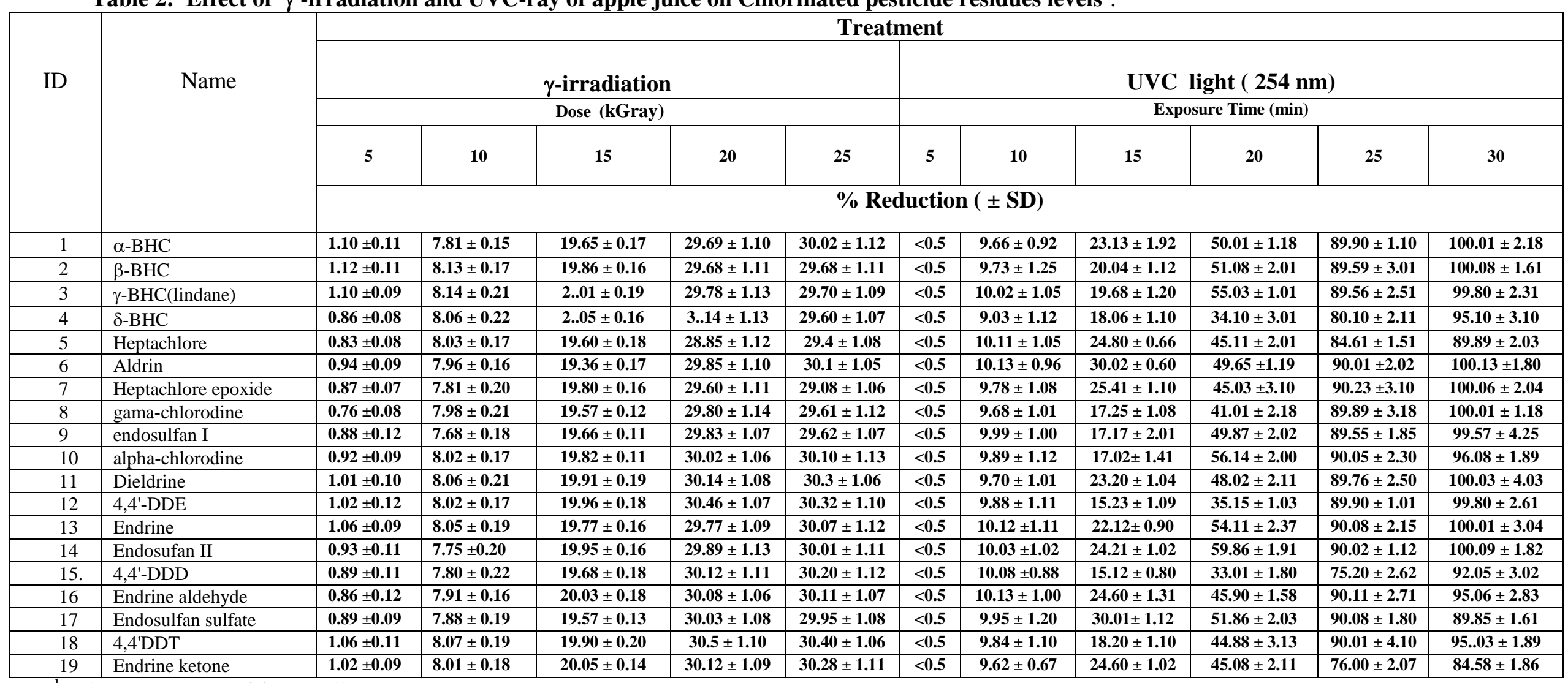

${ }^{1}$ values are means of four replicates $(n=4) \pm$ SD. 

light in food processing is considered to enhance breaking down of particular pesticides present in liquid food commodities such as juices. This result is in agreement with the result obtained by (Mallatou et al., 2003) that the use of Heat treatment has only small effect on OCP's degradation.

\section{Conclusions}

The SPME methods for analyzing OCP'S were found to be an excellent alternative method in multiresidues analysis. The results were equivalent to those obtained by the conventional techniques which involve extraction and clean-up (SPE or Florisil). Therefore, the SPME technique is a valuable method for OCP's analysis that it can be adopted in the future. The UV-light has a powerful effect on OCP's degradation, whereas, $\gamma$-irradiation has limited degradation efficiency on the levels of OCP's in food products. Therefore, the fate of pesticides residues must be studied and evaluated irrespective of degradation percentage before either recommending the use of either UV-light or $\gamma$ irradiation in food processing.

\section{REFERENCES}

Abdul-Wahab A., Dawood R., Abde Maaboud M., Helal S. and Waleed H. (2004).Detection of organochlorine pesticide Residue in samples of cow milk collected from Sohag and Qena governorates. Ass.Univ. Bull.Environ. Res., 7(2): 50-55.

Anonmyous. (1999). UV light provides alternative to heat pasteurization of juices. Food Technol., 53(9):144-150.

Beltan J., Peruga A., Pitarch E., Lopez F.J. (2003). Application of solid-phase microextraction for the determination of pyrethroid residues in vegetable samples by GC-MS. Anal. Bioanal. Chem., 376: 502-511.

Benitez, F. J., Real, F., J., Acero, J. L., and Garcia, C. (2006). Photochemical oxidation processes for the elimination of phenyl-urea herbicides in waters. Journal of Hazardous Materials 138: 278-287.

Bernard W., Amler S. and Amler R. (2004). Pesticide usage and exposure, Pediatrics, 113(4):1030-1036.

Chai M.K., Huat T. G. and Kumasi A. (2006). Method development for the determination of pesticida residues in vegetable and fruits by using solid-phase microextraction. Malaysian Journal of Chemistry, 8(1): 67-71.

Churey J. J. and Padilla-Zakou O. (1998). Apple cider : treatment option to comply with new regulations. J. Assoc. Food Drug Officials. 12:19-25.

Colborn T., Vomsaal F.S. and Soto A. M. (1998). Developmental effects of endocrine disruption chemicals in wildlife and humans, Environ. Health Perspect, 101(4):378-384.

EU. (2006). Council Directive of 24 July 1986 on the fixing of maximum levels for pesticide residues in and on food stuff of animal origin (86-3631EEC).

Frias M.M, Frenich A.G., Vidal M. J., Sanchez M. M., Olea F. and Olea N. (2001). Analysis of lindane, vinclozolin, aldrin,p, $\mathrm{p}^{\prime}$-DDE, o, $\mathrm{p}^{\prime}$ DDT and $\mathrm{p}, \mathrm{p}^{\prime}$ DDT in human serum using gas chromatography with electron capture detection and tandem mass spectrometry Journal of chromatography, 760(8):1-15.

Guerrero-Beltrin J.A. (2004). Advantage and limitation on processing food by UV light, Food Science and Technology International, 10:137-197.

Li C. F. and Bradley R.L.(1968). Degradation of chlorinated hydrocarbon pesticides in milk and butter oil by Ultraviolet Energy. J. Dairy Sci.52(1):27-30

Mallatou H. Pappas $\mathrm{Cp}$ and Albanis TA. (2003).Behavior of pesticides lindane and methyl parathion during manufacture, ripening and storage feta cheese. International Journal of Dairy Technology, 55(4):211-216.

Nandong X., Hongbo W. and Xiaobai XU. (2005). Progress in study on endocrine disrupting pesticides (EDPs) in aquatic environment. Chinese Science bulletin, 50(20): 2257-2266.

Ou X. M., Wang X. G. and Huang D.F. (2003). Progress in studies on pesticides degradation by bacterium (in Chinese), World pesticides, 25(6):30-35.

SAS Institute. (2000). SAS User's guide: Statistics. SAS Institute Inc., Cary, NC.

Sastry S.K., Datta A.K. and Wrobo R.W. (2000). Ultraviolet light in kinetics of microbial inactivation for alternative food processing technologies, J. Food Sci. special supplement, 54(2):45-60

Štêpân R., Tichâ J., Hajslovâ T., Kova and KOlczuk Kocourek V. (2005). Baby food Production chain, Pesticide residues in Fresh apple and products. Food Additive and contaminations, 22(12):1231-1242.

USFDA.(2006). Lindane and other $\mathrm{HCH}$ isomer, EPA risk assessment, EPA-HQ-OPP-2006$0034: 6479-6480$ 
Waliszewski S., Gomez-Arryo S., Infanzon R., Carvajal R., Villalobos-Pietrini P., Trujilo and Maxwell M.(2004).Persistent organochlorine positive levels in bovine fat from Mexico, Food Additive and Contaminations , 21:774788.
Wurl O. and Obbrad J. F. (2005). Organochlorine compound in the marine atmosphere of Singapore. Atmospheric Environment, 39: 7207-7216.

\section{اثر استخدام الأشعة فوق البنفسية و التشعيع بأشعة جامـا لعصير التفاح على متبقيات المبيدات العضوية المكلورة}

$$
\begin{aligned}
& \text { صقر محمد حرزالله } \\
& \text { قسم التغذية و التصنيع الغذائيـ كلية الزر اعة - جامعة مؤتة ـ الكرك-الأردن }
\end{aligned}
$$

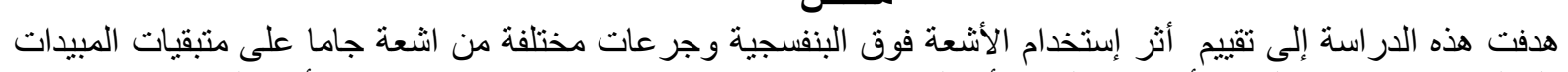

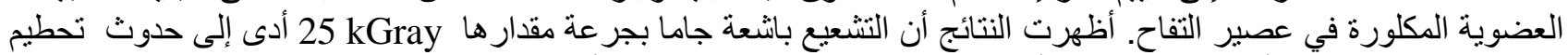

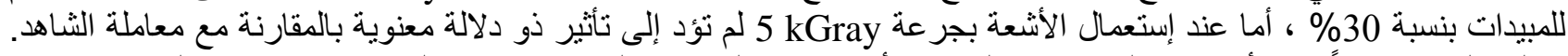

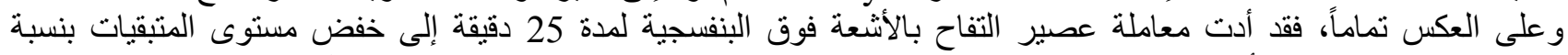

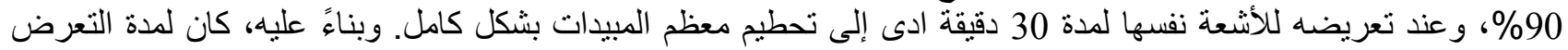

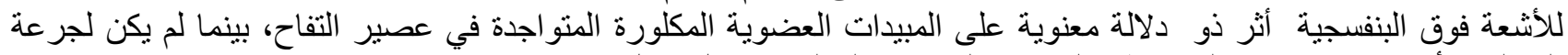

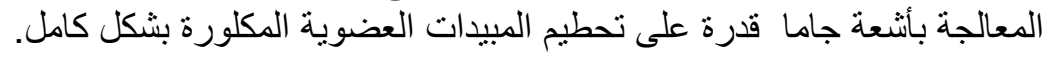

المجلة العلمية لكلية الزراعة - جامعة القاهرة - المجلا (60) العدد الثانى (أبريل 2009):206-212. 